\title{
HUBUNGAN PELAYANAN KONSUMEN DAN FASILITAS PERUSAHAAN TERHADAP KEPUASAN KONSUMEN PADA PT. AVANT GUARD INDONESIA
}

\author{
RINOVIAN RAIS \\ rinovian.rais@ibm.ac.id \\ Program Studi Manajemen \\ Institut Bisnis Muhammadiyah Bekasi
}

\begin{abstract}
The Purpose of this study was to determine the effect of customer service and company facilities on customer satisfaction at PT Avant Guard Indonesia and to determine the variables that have a greater influence between customer services and company facilities on customer satisfaction at PT Avant Guard Indonesia. Based on testing with Chi square $\left(X^{2}\right)$, it is found that there is a significant relationship between customer service and customer satisfaction, or the better the service provided, the better customer satisfiction, For the relationship between company facilities and customer satisfiction, it is found that there is a significant relationship between company facilities and customer satisfaction, or the better the company facilities provided, the better customer satisfaction. From the calculation, it is also known that service has a greater influence, so that that the second Hypothesis can be accepted.
\end{abstract}

\section{Keywords: Customer Services, Company Facilities, Customer Satisfaction}

\section{PENDAHULUAN}

Beberapa tahun terakhir dan setelah krisis ekonomi dan moneter yang terjadi sejak pertengahan tahun 2018 (ekonomi global) dampak siklus ekonomi 10 tahunan dimulai 1998, 2008 dan 2018, belum menunjukkan recovery, di mana lembaga keuangan perbankan yang masih mengalami kesulitan dalam penyaluran kreditnya sehingga mengganggu likuiditas dan belum mampu menggerakkan sektor riil.

\footnotetext{
Banyak dari semua kalangan pedagang, UMKM dan tidak menutup kemungkinan para pengusaha yang mencari jalan alternatif untuk menutupi kebutuhan dana. Kelancaran pengucuran dana merupakan impian untuk memenuhi kebutuhan usaha, baik yang konsumtif maupun produktif. Tidak mengherankan kalau sekarang banyak bermunculan lembaga-lembaga keuangan perbankan maupun lembaga keuangan non bank yang menjanjikan kemudahan dalam hal pengucuran dana secepat mungkin.
}

PT Avant Guard Indonesia sebagai usaha di bidang jasa Arsitektur, perlu mengetahui bagaimana kinerja mereka diterima oleh konsumennya. Untuk dapat memuaskan konsumen, perusahaan dituntut untuk mengetahui faktor-faktor apa saja yang dapat mempengaruhi kepuasan konsumen selama bertransaksi dengan PT Avant Guard Indonesia sehingga dapat ditentukan strategi dalam usaha pengembangan perusahaan.

\section{RUMUSAN MASALAH}

Dari permasalahan di atas peneliti mengidentifikasi beberapa masalah Sebagai berikut:

a) Apakah Pelayanan Konsumen dan Fasilitas Perusahaan mempunyai pengaruh yang berarti terhadap Kepuasan Konsumen PT Avant Guard Indonesia?

b) Manakah variabel yang mempunyai pengaruh lebih besar di antara Pelayanan Konsumen dan Fasilitas Perusahaan terhadap Kepuasan Konsumen PT Avant Guard Indonesia? 


\section{METODE PENELITIAN}

a. Jenis penelitian

Penelitian ini menggunakan metode survey dalam pengumpulan datanya.

b. Obyek Penelitian

Penelitian ini dilakukan pada PT Avant Guard Indonesia.

c. Metode Pengumpulan Data

Pengumpulan data dilakukan dengan cara observasi, kuesioner, dan dokumentasi.

d. Penentuan Ukuran Sampel

Penentuan ukuran sampel yang dilakukan dengan menggunakan cara interval taksiran, dengan rumus sebagai berikut (Umar Husein, 2000): $\mathrm{n}>\mathrm{pq}(\mathrm{Z} \alpha / 2 / \mathrm{e})^{2}$. Dari perhitungan diperoleh hasil 96.04. Dengan demikian dalam penelitian ini diambil 100 responden sehingga memenuhi syarat minimal sebesar 96 responden.

\section{Metode Analisis}

a. Pengujian tingkat Validitas dan reliabilitas Untuk menguji validitas data dari kuisioner digunakan teknik korelasi product moment (Singarimbun, Masri dan Sofyan Effendi. 1995). Untuk menguji reliabilitas digunakan metode genap gasal yaitu memisahkan item nomor ganjil dengan Item nomor genap yang valid, kemudian dicari dengan rumus korelasi product

Metode Spearman Brown di mana Pengujian dilakukan dengan bantuan software SPPS for Windows. Pengujian validitas dilakukan pada 30 sampel. Adapun hasil pengujian validitas variabel pelayanan konsumen (X1) dapat dilihat pada tabel tabel 1.

Tabel 1. Pengujian Validitas dan Realibilitas Item pada variabel pelayanan konsumen.

\begin{tabular}{|c|c|c|c|}
\hline Pertanyaan & $\begin{array}{l}\mathrm{r} \\
\text { hitung }\end{array}$ & $\mathrm{r}$ Tabel & Keterangan \\
\hline 1 & 0,785 & 0,374 & Valid \\
\hline 2 & 0,725 & 0,374 & Valid \\
\hline 3 & 0,429 & 0,374 & Valid \\
\hline 4 & 0,740 & 0,374 & Valid \\
\hline Realibilitas & 0,647 & & Diterima \\
\hline
\end{tabular}

Sumber: Data primer yang diolah monent (Singarimbun, Masri dan Sofyan Effendi. 1995). Untuk menguji reliabilitas selanjutnya digunakan rumus Spearman Brown.

b. Untuk mengetahui pengaruh pelayanan dan fasilitas terhadap kepuasan konsumen digunakan uji Chi square $\left(\chi^{2}\right)$ dengan rumus sebagai berikut (Freddy Rangkuti, 2002):

$X^{2}=\frac{(\mathrm{OIJ}-\mathrm{EIJ}) 2}{\mathrm{EIJ}}[$

Keterangan:

$\mathrm{X} 2$ = Harga dari suatu kai kuadrat

Oij = Nilai sel yang diamati

Eij $=$ Nilai sel yang diharapkan

$\mathrm{Eij}=\operatorname{Pr} \times \operatorname{Pc} \times n$

$\operatorname{Pr}=$ Proporsi baris

$\mathrm{Pc}=$ proporsi kolom

$\mathrm{n}=$ ukuran sampel

\section{HASIL DAN PEMBAHASAN Uji Validitas dan Realibilitas}

Uji validitas dilakukan untuk menguji kesahihan pertanyaan yang dijadikan kuisioner. Analisis validitas dilakukan dengan menggunakan korelasi Product Moment, sedangkan uji reliabilitas dilakukan dengan

Dari tabel 1 dapat diketahui hasil penghitungan validitas dan reliabilitas diperoleh $r$ hitung pada setiap pertanyaan pada variabel pelayanan konsumen lebih besar dibandingkan nilai $r$ tabel sebesar 0,374. Dengan dapat dikatakan tiap item pernyataan dalam variabel pelayanan konsumen adalah valid dan reliabilitas sehingga dapat dijadikan sebagai instrumen penelitian.

Adapun hasil pengujian validitas variabel fasilitas perusahaan $\left(\mathrm{X}^{2}\right)$ dapat dilihat pada tabel 2 . 
Tabel 2. Pengujian validitas dan reliabilitas variabel fasilitas pe rusahaan

$\left(\mathbf{X}^{2}\right)$

\begin{tabular}{|c|c|c|c|}
\hline Pertanyaaan & rHitung & rTabel & Keetrangan \\
\hline 1 & 0,546 & 0,374 & Valid \\
\hline 2 & 0,765 & 0,374 & Valid \\
\hline 3 & 0,607 & 0,374 & Valid \\
\hline Reliabilitas & 0,577 & & Diterima \\
\hline
\end{tabular}

Sumber: Data primer yang diolah

Dari tabel 2 dapat diketahui hasil penghitungan validitas dan reliabilitas diperoleh $r$ hitung pada setiap pertanyaan pada variabel fasilitas perusahaan lebih besar dibandingkan nilai $r$ tabel sebesar 0,374. Dengan dapat dikatakan tiap item pernyataan dalam variabel fasilitas perusahaan adalah valid dan reliabilitas sehingga dapat dijadikan sebagai instrumen penelitian.

Adapun hasil pengujian validitas variabel kepuasan konsumen (Y) dapat dilihat pada tabel 3 .

Tabel 3. Pengujian validitas dan re liabilitas variabel kepuas an konsumen

\begin{tabular}{|c|c|c|c|}
\hline Pertanyaaan & rHitung & rTabel & Keterangan \\
\hline 1 & 0,847 & 0,374 & Valid \\
\hline 2 & 0,711 & 0,374 & Valid \\
\hline 3 & 0,891 & 0,374 & Valid \\
\hline Reliabilitas & 0,873 & & Diterima \\
\hline
\end{tabular}

Sumber: Data primer yang diolah

Dari tabel 3 dapat diketahui hasil penghitungan validitas dan reliabilitas diperoleh $r$ hitung pada setiap pertanyaan pada variabel kepuasan konsumen lebih besar dibandingkan nilai r tabel sebesar 0,374. Dengan demikian dapat dikatakan tiap item pernyataan dalam variabel kepuasan konsumen adalah valid dan reliabilitas sehingga dapat dijadikan sebagai instrumen penelitian.

\section{Analisis Hubungan Pelayanan Konsumen Dengan Kepuasan Konsumen}

Dari hasil perhitungan analisis uji chi square $\left(\chi^{2}\right)$ hubungan antara pelayanan konsumen dengan kepuasan konsumen dapat dilihat pada tabel 4 .

Tabel 4. Hubungan antara pelayanan dengan kepuasan konsumen pada PT Avant Guard Indonesia tahun 2019

\begin{tabular}{|c|c|c|c|c|}
\hline \multirow{2}{*}{$\begin{array}{l}\text { Pelayanan } \\
\text { Konsumen }\end{array}$} & \multicolumn{3}{|c|}{ Kepuasaan Konsumen } & \multirow{2}{*}{ Total } \\
\hline & $\begin{array}{c}\text { Tidak } \\
\text { Puas }\end{array}$ & $\begin{array}{l}\text { Cukup } \\
\text { Puas }\end{array}$ & $\begin{array}{l}\text { Sanga } \\
\text { t Puas }\end{array}$ & \\
\hline \multirow{2}{*}{$\begin{array}{c}\text { Tidak } \\
\text { Memuaska } \\
n\end{array}$} & 17 & 16 & 1 & 34 \\
\hline & $50 \%$ & $\begin{array}{c}47.06 \\
\%\end{array}$ & $\begin{array}{c}2,94 \\
\%\end{array}$ & $\begin{array}{c}100 \\
\%\end{array}$ \\
\hline \multirow{2}{*}{$\begin{array}{c}\text { Cukup } \\
\text { Memuaska } \\
n\end{array}$} & 10 & 41 & 5 & 56 \\
\hline & $\begin{array}{l}17,8 \\
6 \%\end{array}$ & $\begin{array}{c}73,21 \\
\%\end{array}$ & $\begin{array}{c}8,93 \\
\%\end{array}$ & $\begin{array}{c}100 \\
\%\end{array}$ \\
\hline \multirow{2}{*}{$\begin{array}{c}\text { Sangat } \\
\text { memuaska } \\
\text { n }\end{array}$} & 1 & 4 & 5 & 10 \\
\hline & $\begin{array}{l}10 \\
\%\end{array}$ & $40 \%$ & $50 \%$ & $\begin{array}{c}100 \\
\%\end{array}$ \\
\hline \multirow[t]{2}{*}{ Total } & 28 & 61 & 11 & 100 \\
\hline & $\begin{array}{l}28 \\
\%\end{array}$ & $61 \%$ & $11 \%$ & $\begin{array}{c}100 \\
\%\end{array}$ \\
\hline
\end{tabular}

Sumber: Data primer yang diolah

Berdasarkan tabel 4 diketahui dari 100 orang responden teradap 56 orang yang menyatakan pelayanan konsumen yang diberikan PT Avant Guard Indonesia cukup memuaskan dan 41 orang di antaranya menyatakan hal tersebut berdampak pada peningkatan rasa puas. Dari tabel itu juga dapat 
diketahui terdapat 10 orang yang menyatakan pelayanan konsumen yang diberikan PT Avant Guard Indonesia sangat memuaskan dan sebanyak 34 orang menyatakan bahwa pelayanan konsumen yang diberikan tidak memuaskan.

Berdasarkan tabel di atas dapat disimpulkan bahwa semakin baik pelayanan konsumen yang diberikan maka hal tersebut berdampak pada kepuasan yang dirasakan konsumen.

Berdasarkan pengujian dengan Chi square $\left(\mathrm{X}^{2}\right)$ tersebut diperoleh $\mathrm{Chi}$ square hitung sebesar 28,231 dengan nilai signifikan sebesar 0,000. Hal ini berarti terdapat hubungan yang signifikan antara pelayanan konsumen dan kepuasan konsumen, atau semakin baik pelayanan konsumen yang diberikan, semakin baik pula kepuasan konsumennya.

Analisis hubungan fasilitas Perusahaan dengan kepuasan konsumen

Hasil perhitungan analisis uji chi square $\left(\mathrm{X}^{2}\right)$ hubungan antara fasilitas Perusahaan dengan kepuasan konsumen dapat dilihat pada tabel 5 .

Tabe 15. Hubungan antara fasilitas perusahaan dengan kepuasan konsumen pada PT Avant Guard Indonesia tahun 2019

\begin{tabular}{|l|c|c|c|l|}
\hline \multirow{2}{*}{ Fasilitas } & \multicolumn{3}{|c|}{ Kepuasaan Konsumen } & Total \\
\cline { 2 - 5 } & Tidak Puas & Cukup Puas & Sangat Puas & \\
\hline Tidak Memuaskan & 0 & 4 & 0 & 4 \\
\hline & $0 \%$ & $100 \%$ & $0 \%$ & $100 \%$ \\
\hline Cukup Memuaskan & 27 & 37 & 3 & 67 \\
\hline & $40,30 \%$ & $55,22 \%$ & $4,48 \%$ & $100 \%$ \\
\hline Sangat memuaskan & 1 & 20 & 8 & 29 \\
\hline & $3,45 \%$ & $68,97 \%$ & $27,59 \%$ & $100 \%$ \\
\hline Total & 28 & 61 & 11 & 100 \\
\hline & $28 \%$ & $61 \%$ & $11 \%$ & $100 \%$ \\
\hline
\end{tabular}

Sumber: Data primer yang diolah

Berdasarkan tabel 5 di atas dapat diketahui dari 100 orang responden, 67 orang di antaranya menyatakan bahwa fasilitas perusahaan yang disediakan cukup memuaskan, 29 orang di antaranya menyatakan sangat puas dan terdapat 4 orang yang menyatakan bahwa fasilitas perusahaan yang ditawarkan PT Avant Guard Indonesia tidak memuaskan.

Berdasarkan pengujian dengan Chi square $\left(\mathrm{X}^{2}\right)$ tersebut diperoleh Chi square hitung sebesar 22,932 dengan nilai signifikan sebesar 0,000 . Hal ini berarti terdapat hubungan yang signifikan antara fasilitas perusahaan dan kepuasan konsumen, atau semakin 
baik fasilitas yang diberikan, semakin baik pula kepuasan konsumennya.

Untuk mengetahui variabel yang memberikan pengaruh lebih besar antara pelayanan konsumen dan fasilitas perusahaan terhadap kepuasan konsumen digunakan perbandingan nilai chi square dan hasilnya dapat dilihat pada tabel 6 sebagai Berikut:

Tabel 6. Perbandingan nilai chi square

\begin{tabular}{|c|c|c|}
\hline Nomor & Variabel & $\begin{array}{c}\text { Chi } \\
\text { Square }\end{array}$ \\
\hline 1. & $\begin{array}{c}\text { Pelayanan } \\
\text { Konsumen }\end{array}$ & 28,231 \\
\hline 2. & $\begin{array}{c}\text { Fasilitas } \\
\text { Perusahaan }\end{array}$ & 22,932 \\
\hline
\end{tabular}

Sumber: Data primer yang diolah

Berdasarkan ringkasan hasil perhitungan pada tabel 6 dapat diketahui bahwa nilai Chi square (X) variabel pelayanan konsumen lebih besar dibandingkan nilai Chi square (X) variabel fasilitas perusahaan $(28,231>$ 22,932). Hal ini menunjukkan bahwa pelayanan konsumen memberikan pengaruh lebih besar terhadap kepuasan konsumen dibandingkan dengan fasilitas perusahaan, sehingga hipotesis kedua dapat diterima.

\section{KESIMPULAN}

Hasil penelitian menunjukkan bahwa pelayanan konsumen dan fasilitas perusahaan memberikan pengaruh terhadap kepuasan konsumen pada PT Avant Guard Indonesia. Hal ini menunjukkan bahwa semakin baik pelayanan konsumen yang diberikan dan semakin baik fasilitas perusahaan yang disediakan, maka akan semakin baik pula kepuasan konsumen yang dirasakan konsumennya.

Pelayananan Konsumen memberikan pengaruh yang lebih besar terhadap Kepuasan Konsumen dibandingkan dengan Fasilitas Perusahaan. Hal ini menunjukkan bahwa pelayanan konsumen yang diberikan PT Avant Guard Indonesia memberikan dampak yang lebih berarti dibandingkan dengan fasilitas perusahaan yang disediakan.

Dalam meningkatkan kepuasan konsumen, manajemen PT Avant Guard Indonesia harus terus mempertahankan bahkan harus lebih meningkatkan pelayanan konsumen yang harus diberikan kepada konsumen, Selain itu manajemen PT Avant Guard Indonesia juga harus memperhatikan Fasilitas Perusahaan pendukung yang disediakan agar kepuasan konsumen dapat ditingkatkan lagi.

Kepuasan konsumen dapat lebih optimal lagi apabila manajemen PT Avant Guard Indonesia lebih memaksimalkan dalam pelayanan konsumen yang harus diberikan kepada konsumen.

Berbagai faktor yang mungkin dilakukan antara lain memperlakukan konsumen tanpa memandang status sosial. Selain itu, pegawai juga harus bersikap lebih profesional dengan memberikan pelayanan konsumen dengan cepat tanpa menimbulkan kesalahan agar konsumen lebih percaya dan tetap loyal kepada PT Avant Guard Indonesia. 


\section{DAFTAR PUSTAKA}

Abdullah, Thamrin dan Francis Tantri. 2016. Manajemen Pemasaran, PT Raja Grafindo Persada, Depok

Abdurrahman, H. 2015. Manajemen Pemasaran. Penerbit CV. Pustaka Setia, Bandung

Ahiyoso, Srikandi Kumadji, dan Anriani Kusumawati. 2017: Pengaruh Kualitas Layanan terhadap Citra perusahaan dan Loyalitas Pelanggan (survey pada pelanggan digital Printing Surabaya), Jurnal Administrasi Bisnis,Vol.50, No.4,

Amirullah. 2015. Pengantar Manajemen. Mitra Wacana Media, Jakarta

Buchari Alma., 2016 Manajemen Pemasaran dan Pemasaran Jasa. Penerbit Alfabeta, Bandung

Candy, 2016 : Kualitas Pelayanan Jasa Percetakan Terhadap Kepuasan Konsumen Pada PT. Tri Jaya Mandiri, Bisma, Vol 1, No. 8,

Darmawati. 2016: Pengaruh Kualitas Pelayanan Terhadap Loyalitas Pelanggan Dalam Memakai Jasa Percetakan CV. Rahmat Nur di Semarang, Ejournal Ilmu Administrasi Bisnis, Vol 4, No. 1, 157-171

Fandy Tjiptono dan Anastasia Diana, 2019, Konsep, Pengukuran dan Strategi, Penerbit Andi, Jogyakarta

Fandy, Tjiptono. 2016. Service, Quality \& satisfaction. Yogyakarta. Andi.

Harman Malau. 2017. Manajemen Pemasaran. Alfabeta, Bandung.
Hilman Ardianta Putra, dan Nganto. 2017: Pengaruh Kualitas Pelayanan Terhadap Loyalitas Konsumen Melalui Kepuasan Konsumen Sebagai Variabel Intervening (Studi Kasus Pada Konsumen PT. Lontara Media Digital Printing Semarang), Diponegoro Journal of Social And Political, Vol 1, No.8, $1-8$

Jihan Nafisa Dan I Made Sukresna. 2018: Analisis Pengaruh Kualitas Layanan, Harapan Kinerja dan Citra Perusahaan Terhadap Loyalitas Pelanggan Melalui Kepuasan Pelanggan Sebagai Variabel Intervening (Studi Kasus Pada Percetakan Digital di Malang), Diponegoro Journal of Management, Vol 7, No. 3, 1-26

Kotler, P. and Keller, K.L. 2016. Marketing Management, 15th Edition New Jersey: Pearson Pretice Hall, Inc.

Lovelock, Christopher., Patterson, P. dan Wirtz, J. 2016. Services Marketing: An Asia-Pasific and Australian Perspective, Sixth Edition, Pearson, Australia.

Majid esmaeilpour, and sahebeh barjoe. 2016: The Effect Of Corporate Image On Costomer Satifaction Through Brand Equity, Advances In Management \& Applied Economics, Vol.6, No.4,

Malayu S.P, Hasibuan. 2016. Manajemen Sumber Daya Manusia. Edisi Revisi. Penerbit PT Bumi Aksara, Jakarta 
M. N. Nasution, 2015 Manajemen Mutu Terpadu. Penerbit Ghalia Indonesia, Bogor

Nilam Sari. 2018: Service Quality, Company Image, Trust, and ist Influace on Customers Satisfaction and Loyalty at Bank Shariah Mandiri (BSM) Meulaboh Branch Office, The International Journal of Social, Vol.6, No.2, 235-252

Ridhotullah, Subeki \& Jauhar, Mohammad. 2015. Pengantar Manajemen. Penerbit Prestasi Pustakaraya, Jakarta

Sugiyono. 2017. Metode Penelitian

Kuantitatif Kualitataif dan Kombinasi (Mixed

Methods). Penerbit Alfabeta, Bandung

Syamsu, Marlin. 2017: Analisis

Pengaruh Kualitas

Layanan dan Kualitas

Produk Terhadap

Kepuasan dan Loyalitas

Pelanggan Layanan

Data 4G (Studi Kasus

PT. Internux Operations

Excellence), Vol 9, No.

2 ,

Vina Islami. 2018: Pengaruh

Kualitas Pelayanan

Terhadap Kepuasan

Pelanggan (Studi Kasus

Pada Screen Printing Emsiia Production), Perspektif, Vol 16, No.

2. 